OPEN ACCESS

Edited by:

Yong Zhang,

Harbin Institute of Technology,

China

Reviewed by:

Shaoheng Cheng,

Jilin University, China

Hong-Ying Zhuo,

Tsinghua University, China

${ }^{*}$ Correspondence:

Liyun Jiang

lyjiang2014@126.com

Specialty section:

This article was submitted to

Solar Energy,

a section of the journal

Frontiers in Energy Research

Received: 27 April 2021

Accepted: 26 May 2021

Published: 16 June 2021

Citation:

Jiang J, Jiang L, Rong P, Wu K, Yang $Q$

and Yu Q (2021) Properties and

Configurations of B-N Co-Doped $\mathrm{ZnO}$

Nanorods Fabricated on ITO/

PET Substrate.

Front. Energy Res. 9:700901.

doi: 10.3389/fenrg.2021.700901

\section{Properties and Configurations of B-N Co-Doped ZnO Nanorods Fabricated on ITO/PET Substrate}

\author{
Jianchao Jiang ${ }^{1}$, Liyun Jiang ${ }^{1 *}$, Ping Rong ${ }^{1}$, Kechen $W u^{2}$, Qingqing $\mathrm{Yang}^{1}$ and Qi $\mathrm{Yu}^{1}$ \\ ${ }^{1}$ School of Physics and Telecommunication Engineering, School of Materials Science and Engineering, Shaanxi University of \\ Technology, Hanzhong, China, ${ }^{2}$ Fujian Key Laboratory of Functional Marine Sensing Materials, Minjiang University, Fuzhou, China
}

Based on flexible materials, optoelectronic devices with optoelectronic technology as the core and flexible electronic devices as the platform are facing new challenges in their applications, including material requirements based on functional electronic devices such as lightness, thinness, and impact resistance. However, there is still a big gap between the current preparation technology of flexible materials and practical applications. At present, the main factors restricting the more commercial development of flexible materials include preparation conditions and performance. In this work, B-N co-doped ZnO nanorod arrays (NRAs) were successfully synthesized on the polyethylene terephthalate (PET) substrate coated with indium tin oxide (ITO) by the hydrothermal method. Based on the density functional theory, the effect of B-N co-doping on the electronic structure of $\mathrm{ZnO}$ was calculated; the incorporation of $\mathrm{B}$ and $\mathrm{N}$ led to an increase in the lattice constant of $\mathrm{ZnO}$. The B-N co-doped $\mathrm{ZnO}$ has obvious rectification characteristics with the positive conduction voltage of $2 \mathrm{~V}$ in the $\mathrm{I}-\mathrm{V}$ curve.

Keywords: co-doped, ITO/PET, I-V characteristic, heterojunction, ZnO

\section{INTRODUCTION}

Flexible electronics was once recognized as one of the top ten scientific and technological achievements in the world, and it is very likely to bring a new generation of information technology revolution. Different from traditional electronic devices, flexible electronic characters have higher flexibility, better stretch, and greater bendability without damaging the performance of electronic devices. Therefore, it currently has broad application prospects in the fields of information, medical treatment, and energy. Based on this background, flexible semiconductor materials have exhibited high flexibility and strain sensitivity, which were an ideal choice for flexible optoelectronics (Du et al., 2020; Wang et al., 2017). As a transparent conductive oxide film, indium tin oxide (ITO) is mainly characterized by its conductivity and optical transparency and is widely used in various electronic devices. Polyethylene terephthalate (PET) is a saturated thermoplastic polymer with good physical and chemical properties, including high impact strength, corrosion resistance, transparency, and safety. As a good flexible transparent electrode material, ITO/PET is obtained by sputtering ITOconductive film coating on the PET base material and annealing at high temperature. With high light transmittance and conductivity, ITO/PET has been a perfect choice for optoelectronic materials, such as flexible solar cells and flexible transparent circuit boards (Marciel et al., 2021). ZnO is one of the most attractive semiconductor materials in the past decade. It has a theoretical specific volume as large as 2.3 times that of graphite, a wide band gap up to $3.75 \mathrm{eV}$, and an exciton binding energy up to $60 \mathrm{meV}$ (Klingshirn, 2010). 
Due to the similar thermal expansion coefficients of ITO and $\mathrm{ZnO}, \mathrm{ZnO}$ grown on ITO can effectively avoid cracks caused by stress changes and compensate for defects in the growth process (Zhang et al., 2017; Sima et al., 2013). In order to enhance the p-type electrical properties of $\mathrm{ZnO}$, some studies have begun to explore the influence of doped heteroatoms on the electrical properties of $\mathrm{ZnO}$. It is found that $\mathrm{N}$-doping can change the conduction type of $\mathrm{ZnO}$, but high resistivity is not conducive to its application in the field of optoelectronics. Since 2004, Al-N, In-N, Ga-N, Ag-N, and Sn-N have also been studied to improve the electrical properties of $\mathrm{ZnO}$ films besides $\mathrm{B}-\mathrm{N}$ co-doping (Zhang et al., 2017; Xu et al., 2017; Farooq et al., 2020; Siva et al., 2020; Kaur et al., 2021). It is found that co-doping of B-N can effectively reduce the resistivity and further increase the carrier concentration. The Burstein-Moss effect increases the energy gap of the B-N co-doped film, thereby increasing the light utilization efficiency by stacking absorbers with different energy gaps (Nripasree et al., 2017). At present, co-doping $\mathrm{ZnO}$ with group III and V elements can be utilized to improve the acceptor solubility so as to enhance the electrical properties of the ZnO film (Yamamoto et al., 2001; Bian et al., 2004). If these technologies can be applied more efficiently to potential semiconductor structure (SCS) devices including biosensors, electrical equipment, and gas sensors, it is quite promising and has huge economic benefits (Sun et al., 2015; Beitollahi et al., 2020; Hwang et al., 2020; Ra et al., 2020; Zhang et al., 2020). Based on this, we devote to promoting the application of $\mathrm{ZnO}$ nanorod array (NRA) SCSs by adjusting the structures and properties.

$\mathrm{B}-\mathrm{N}$ co-doped $\mathrm{ZnO}$ is mainly achieved by radio-frequency magnetron sputtering and pulsed laser deposition. Liu et al. used pulsed laser deposition technology to grow B-N co-doped $\mathrm{ZnO}$ on a sapphire substrate (Liu et al., 2008). Datta et al. reported on the observation of stable p-type conductivity in B-N co-doped epitaxial $\mathrm{ZnO}$ thin films grown by pulsed laser deposition (Sahu et al., 2016). Soudi et al. used radio-frequency magnetron sputtering to prepare a $\mathrm{ZnO}$ film on an ITO-coated PET substrate. The film has good optical confinement properties and has shown great applications in non-linear optical devices, including optical switches and optical storage (Soudi et al., 2021). Wang et al. proposed a low-cost ITO/ZnO memory device/TaN sandwich structure with excellent bipolar resistance switching characteristics and ultra-low and uniform operating voltage. Its application prospects in neuromorphological calculations are very broad (Wang et al., 2020). However, due to the limitations of the deposition rate, output energy, equipment cost, and deposition scale of pulsed laser deposition technology, industrial production and application are facing huge challenges. The magnetron sputtering technology with the advantage of strong adhesion, high speed, and low temperature and damage is worth exploring to prepare $\mathrm{B}-\mathrm{N}$ co-doped $\mathrm{ZnO}$ on the ITO/PET substrate.

In this work, the $\mathrm{ZnO}$ seed layer was grown on the ITO/PET substrate by magnetron sputtering technology. On this basis, the $\mathrm{B}-\mathrm{N}$ co-doped $\mathrm{ZnO}$ NRAs were further prepared by hydrothermal technique. According to the establishment of the model, we attempt to understand the atomic configuration of B-N co-doped $\mathrm{ZnO}$. In addition, we further investigate the influence of
B-N co-doping on $\mathrm{ZnO}$ by examining different doping sites via first-principle calculations. Finally, the current-voltage (I-V) characteristics of the constructed $\mathrm{B}-\mathrm{N}$ co-doped $\mathrm{ZnO}$ on the ITO/PET flexible substrate were tested in order to analyze system carrier transport mechanisms and further study the electrical performance.

\section{MATERIALS AND METHODS}

All reagents used in the experimental process were analytically pure. In order to hydrothermally grow $\mathrm{ZnO}$ nanostructures, zinc nitrate hexahydrate $\left(\mathrm{Zn}\left(\mathrm{NO}_{3}\right)_{2} \cdot 6 \mathrm{H}_{2} \mathrm{O}\right)$ and hexamethylenetetramine (HMT, $\mathrm{C}_{6} \mathrm{H}_{12} \mathrm{~N}_{4}$ ) were exactly weighed using an analytical balance with an accuracy of $10^{-4} \mathrm{~g}$ and were dissolved in deionized water, producing precursor solution of $40 \mathrm{ml}$ at a concentration of $0.05 \mathrm{M}$. Boric acid $\left(\mathrm{H}_{3} \mathrm{BO}_{3}\right)$ and ethylenediamine $\left(\mathrm{C}_{2} \mathrm{H}_{8} \mathrm{~N}_{2}\right)$, at a concentration of $0.15 \mathrm{M}$, which provided the source of boron, were mixed with the as-prepared solution and stirred with a magnetic mixer for $30 \mathrm{~min}$. Moreover, using a small ion-sputtering apparatus, a thin seed layer of $\mathrm{ZnO}$ was sputtered onto the surface of the astreated PET-ITO substrate with the size of $6 \mathrm{~cm} \times 8 \mathrm{~cm}$ to reduce the lattice mismatch between $\mathrm{ZnO}$ and the substrate. Among that, the surface resistivity of the PET-ITO flexible substrate is $30 \Omega / s q(19)$, which is lower than that of pure PET $(60 \Omega / \mathrm{sq})$ but higher than that of the ITO substrate $(14 \Omega / \mathrm{sq})$ (20). The process parameters were as follows: sputtering time, $5 \mathrm{~min}$; sputtering current, 6-8 $\mathrm{mA}$; and vacuum pressure, 0.1 mbar. With that, PET-ITO coated with the seed layer was dipped into the as-obtained aqueous solution and sealed by means of plastic wrap. Finally, the device was transferred to an electric oven and heated at a constant temperature of $90^{\circ} \mathrm{C}$ for $5 \mathrm{~h}$, so as to develop the B-N codoped $\mathrm{ZnO}$ nanostructure. After cooling to room temperature $\left(20-25^{\circ} \mathrm{C}\right)$, the product was gradually washed with distilled water and then dried naturally in air.

\section{RESULTS AND DISCUSSION}

Figure 1A shows the photograph of the flexible $\mathrm{B}-\mathrm{N} \mathrm{ZnO}$ fabricated on ITO/PET under the illumination of white fluorescent light. In order to estimate the transparency properties of vertically aligned $\mathrm{ZnO}$ NRAs on ITO/PET, the transmittance was calculated via the rigorous coupled-wave analysis simulation that could accurately predict the transmittance of nanostructures by solving the Maxwell equation with spatial harmonics (Chiu et al., 2008). The optical transmission efficiency was acquired from the transmitted diffraction elements through diffraction electromagnetic energy, which were concluded through satisfying the fringe conditions from the specific region face (Lee et al., 2011). Figure 1B shows the contour plot of calculated transmittances as a function of the height of $\mathrm{ZnO}$ nanorods and the corresponding three-dimensional (3D) modeling of $\mathrm{ZnO}$ NRAs. In the wavelength range of $300-400 \mathrm{~nm}$, whether $\mathrm{ZnO}$ NRAs are 

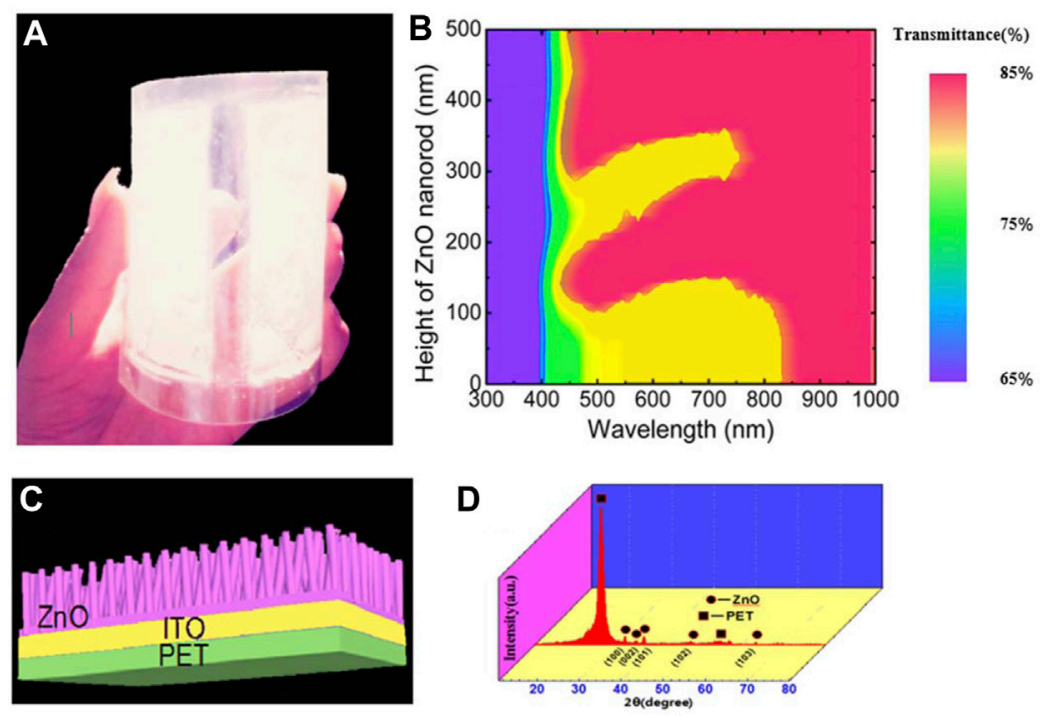

FIGURE 1 | (A) Photograph of B-N ZnO on the ITO/PET substrate, (B) ZnO contour plot of transmittances and 3D modeling of ZnO, (C) schematic diagram of the complex, and (D) XRD patterns of the sample.

deposited on the ITO/PET surface has almost no effect on the light transmittance, showing a low transmittance of about $65 \%$. ITO/PET without $\mathrm{ZnO}$ NRAs (i.e., the height of $\mathrm{ZnO}$ nanorods is zero) exhibited low transmittances $<80 \%$ over a wavelength range of $450-760 \mathrm{~nm}$. For the $\mathrm{ZnO}$ seed-coated ITO/PET, the transmittance was slightly increased as compared to that of bare ITO/PET. This would be caused by the fact that the deposited $\mathrm{ZnO}$ thin film $(30 \mathrm{~nm})$ could decrease the difference in refractive index between air and ITO, the phenomenon that reduced the Fresnel reflections. Meanwhile, the $\mathrm{ZnO}$ height was enhanced and the transmittance was grown. Indeed, this increase in transmittance is due to the effective refractive index (neff) of $\mathrm{ZnO}$ NRAs which relaxes the difference in refractive index between air and the ITO/ PET substrate, thus leading to an antireflection property (Yan et al., 2007; Tian et al., 2009). Based on the effective medium theory, the neff can be obtained by neff $=\left[\mathrm{f}_{\mathrm{ZnO}} \mathrm{n}_{\mathrm{ZnO}}{ }^{2 / 3}+\mathrm{f}_{\text {air }} \mathrm{n}_{\text {air }}{ }^{2 / 3}\right]^{3 / 2}$, where $\mathrm{n}_{\mathrm{ZnO}} / \mathrm{n}_{\text {air }}$ and $\mathrm{f}_{\mathrm{ZnO}} / \mathrm{f}_{\text {air }}$ are the refractive index and volume fraction of $\mathrm{ZnO} /$ air, respectively. When the height of $\mathrm{ZnO}$ nanorods was increased, somewhat fluctuations of transmittance were caused by the fact that the $\mathrm{ZnO}$ NRAs serve as an interference layer with an effectively graded refractive index profile. Figure 1C shows a schematic diagram of hydrothermal growth of $\mathrm{ZnO}$ NARs on ITO/PET. From the XRD patterns of ZnO NRAs on ITO/PET, as shown in Figure 1D, the dominant XRD peak of $\mathrm{ZnO}$ (002) appeared at $34.44^{\circ}$. The two broad XRD peaks of PET were also observed at 46.83 and $53.74^{\circ}$.

Based on the density functional theory, the interstitial $B\left(B_{i}\right)$ and the substitutional $\mathrm{B}$ defect at the $\mathrm{Zn}$ site $\left(\mathrm{B}_{\mathrm{Zn}}\right)$ and the interstitial $\mathrm{B}$ $\left(\mathrm{B}_{\mathrm{i}}\right)$ and the substitutional $\mathrm{N}$ defect at the $\mathrm{O}$ site $\left(\mathrm{N}_{\mathrm{O}}\right)$ are optimized and calculated by using the CASTEP code in Materials Studio (Segall et al., 2002). The $2 \times 2 \times 2$ supercell model and periodic boundary conditions are used. The ion-electron interaction was described by the projected augmented wave (PAW) method (Blöchl et al., 1994), and the electron exchange-correlation was represented by the
Perdew-Burke-Ernzerhof (PBE) functional (Perdew et al., 1998). The calculated mass is hyperfine, the plane wave truncation energy is $\mathrm{E}_{0}=600 \mathrm{eV}$, the convergence accuracy is $1 \times 10^{-5} \mathrm{eV} \cdot$ atom $^{-1}$, the force acting on each atom is not more than $1 \times 10^{-6} \mathrm{eV} \cdot$ atom $^{-1}$, and the internal stress is less than $0.05 \mathrm{GPa}$.

Figures 2A,B show the atomic configuration of $\mathrm{ZnO}$ of $\mathrm{B}_{\mathrm{i}}-\mathrm{B}_{\mathrm{Zn}}$ and DOS for pure $\mathrm{ZnO}$ and $\mathrm{B}_{\mathrm{i}}-\mathrm{N}_{\mathrm{O}} \mathrm{ZnO}$, respectively. $\mathrm{ZnO}$ $\left(\mathrm{B}_{\mathrm{i}}-\mathrm{B}_{\mathrm{Zn}}\right)$ has a similar distribution of DOS to pure $\mathrm{ZnO}$. Figures 2D,E show the atomic configuration of $\mathrm{B}_{\mathrm{i}}-\mathrm{N}_{\mathrm{O}} \mathrm{ZnO}$ and $\mathrm{DOS}$ for pure $\mathrm{ZnO}$ and $\mathrm{B}_{\mathrm{i}}-\mathrm{B}_{\mathrm{Zn}} \mathrm{ZnO}$. In order to determine the effect of $\mathrm{B}-\mathrm{N}$ co-doping on the structure of $\mathrm{ZnO}$, the supercell structures of $\mathrm{ZnO}, \mathrm{B}_{\mathrm{i}}-\mathrm{B}_{\mathrm{Zn}} \mathrm{ZnO}$, and $\mathrm{B}_{\mathrm{i}}-\mathrm{N}_{\mathrm{O}}$ $\mathrm{ZnO}$ were optimized. The lattice parameters of $\mathrm{ZnO}$ are $\mathrm{a}=$ $0.3250 \mathrm{~nm}$ and $\mathrm{c}=0.5206 \mathrm{~nm}$, which are in good agreement with the experimental values, and the error ratio c/a is less than $1 \%$, indicating that the calculation method and parameter setting are reasonable and the calculation results are reliable (Keskenler et al., 2014). In addition, the lattice parameters of $\mathrm{B}_{\mathrm{i}}-\mathrm{N}_{\mathrm{O}} \mathrm{ZnO}$ are $\mathrm{a}=0.6499 \mathrm{~nm}$ and $\mathrm{c}=1.0411 \mathrm{~nm}$, which indicates that the lattice parameters of doped $\mathrm{ZnO}$ increase in the direction of a and $c$ axes, resulting in the lattice stretching of $\mathrm{ZnO}$ and lattice distortion causing internal dipole, hindering the electron-hole recombination, which can effectively separate the hole-electron pairs, thus affecting the photoelectric properties of $\mathrm{ZnO}$ (Prakash et al., 2015). The DOS of $\mathrm{ZnO}_{\mathrm{i}}-\mathrm{B}_{\mathrm{Zn}}$ shifted to the left compared with that of pure $\mathrm{Zn}$, which means that the structure of $\mathrm{ZnO}$ $\mathrm{B}_{\mathrm{i}}-\mathrm{B}_{\mathrm{Zn}}$ was stable.

Figures $2 \mathrm{C}, \mathrm{F}$ show the band structure for $\mathrm{ZnO} \mathrm{B}_{\mathrm{i}}-\mathrm{B}_{\mathrm{Zn}}$ and $\mathrm{B}_{\mathrm{i}}-\mathrm{N}_{\mathrm{O}} \mathrm{ZnO}$, respectively. Compared with the band gap of pure $\mathrm{ZnO}(0.74 \mathrm{eV})$, the band gap for $\mathrm{B}_{\mathrm{i}}-\mathrm{B}_{\mathrm{Zn}} \mathrm{ZnO}$ is $0.14 \mathrm{eV}$. The band gap for $\mathrm{B}_{\mathrm{i}}-\mathrm{N}_{\mathrm{O}} \mathrm{ZnO}$ is $0.44 \mathrm{eV}$. The calculated band gap of $\mathrm{ZnO}$ is quite different from the experimental value $(3.37 \mathrm{ev})$. The main reason is that GGA is jellium-based XC energy functionals that suffer from i) an incomplete cancellation of the artificial Hartree 


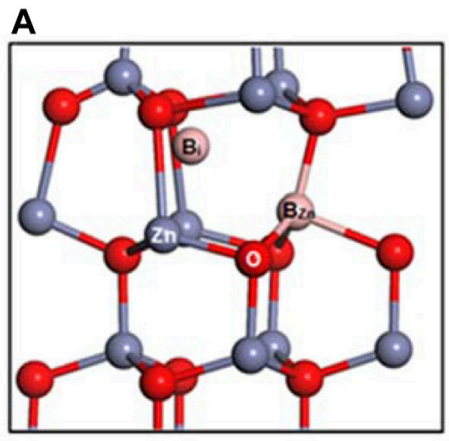

D

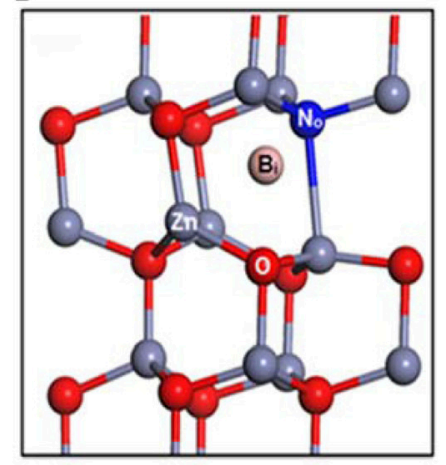

B

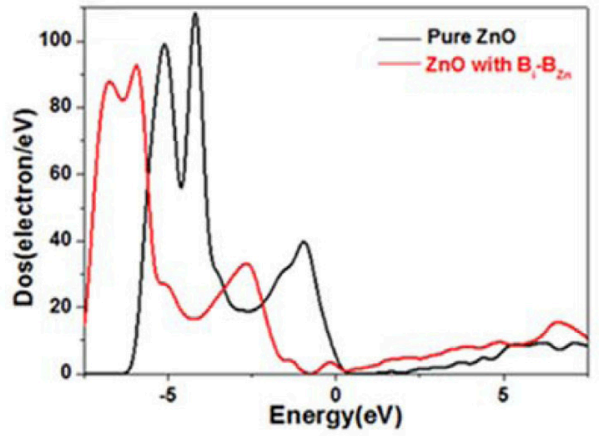

E

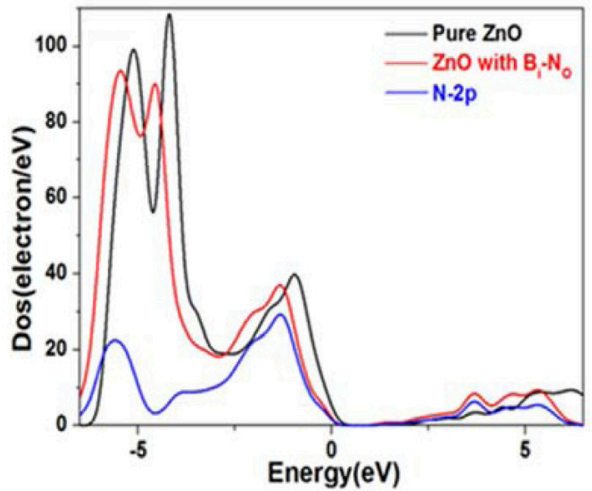

C

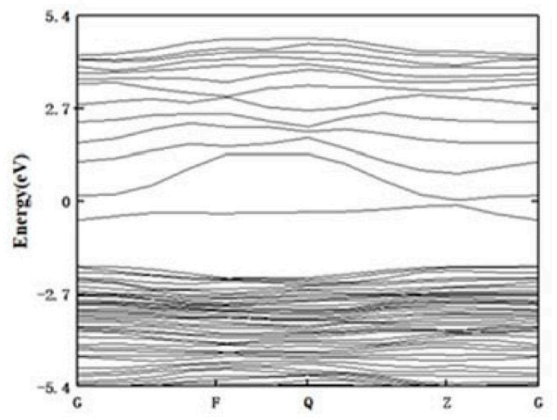

F

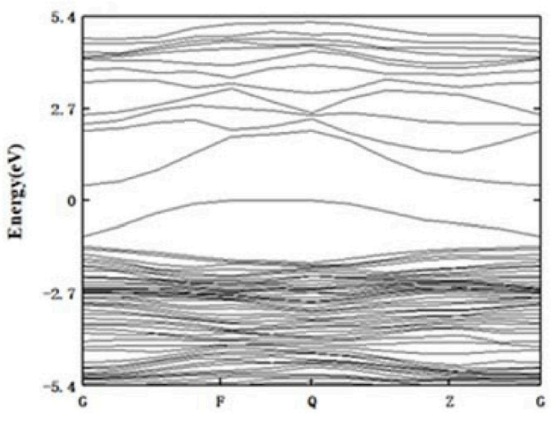

FIGURE 2 | (A) Atomic configuration of $\mathrm{B}_{i}-\mathrm{B}_{\mathrm{Zn}} \mathrm{ZnO}$, (B) DOS for pure $\mathrm{ZnO}$ and $\mathrm{B}_{\mathrm{i}}-\mathrm{N}_{\mathrm{O}} \mathrm{ZnO}$, (C) band structure for pure $\mathrm{ZnO}$ and $\mathrm{B}_{i}-\mathrm{N}_{\mathrm{O}} \mathrm{ZnO}$, (D) atomic configuration of $\mathrm{B}_{\mathrm{i}}-\mathrm{N}_{\mathrm{O}} \mathrm{ZnO}$, (E) DOS for pure $\mathrm{ZnO}$ and $\mathrm{B}_{\mathrm{i}}-\mathrm{B}_{\mathrm{Zn}} \mathrm{ZnO}$, and (F) band structure for $\mathrm{B}_{\mathrm{i}}-\mathrm{N}_{\mathrm{O}} \mathrm{ZnO}$.

self-interaction and ii) the lack of the integer discontinuity in the exchange and correlation energy upon adding an electron. In addition, the overestimation of the pd repulsion and, hence, too high position of the VBM in energy are due to the too shallow $\mathrm{d}$ bands in GGA (Wróbel et al., 2009). By analyzing the energy band structure and density of states of $\mathrm{B}_{\mathrm{i}}-\mathrm{N}_{\mathrm{O}}$, it can be found that compared with those of intrinsic $\mathrm{ZnO}$, because the Fermi level is in the impurity level, the band gap is reduced and the conductivity is enhanced. Moreover, these impurity levels can effectively separate the photogenerated carriers produced by $\mathrm{ZnO}$ and affect the photoelectric properties.

Compared with those of pure $\mathrm{ZnO}$, the impurity levels with lower density of states are formed near the Fermi level. These impurity levels can effectively separate the photogenerated carriers produced by $\mathrm{ZnO}$ and enhance the effective utilization of visible light in $\mathrm{ZnO}$. Based on the theoretical analysis, the system of non-metal co-doped $\mathrm{ZnO}$ has a smaller band gap and produces impurity energy levels. Therefore, less energy is required for $\mathrm{ZnO}$ electronic transitions. Combining the codoped $\mathrm{ZnO}$ with the flexible material ITO/PET provides more applications in optoelectronic devices.

Figure 3A illustrates the I-V characteristics of the B-N codoped $\mathrm{ZnO}$ ITO/PET substrate, and the illustration shows a schematic diagram of the diode. PET and ITO on the top of $\mathrm{ZnO}$ NRAs are used as the anode and cathode, respectively. Conductive silver paste is used to connect the copper wire with the two electrodes of the diode, which can be used as the Schottky contact to form a closed circuit. As shown in Figure 3A, the asymmetry of the $\mathrm{I}-\mathrm{V}$ curve indicates that the diode has a certain rectification characteristic, and the positive conduction voltage is $2 \mathrm{~V}$. From the I-V characteristic results, when the bias voltage is increased to $5 \mathrm{~V}$, the current can reach $\sim 1.7 \mathrm{ma}$. At $-5 \mathrm{~V}$, the reverse leakage current is only $0.1 \mathrm{~mA}$, so the rectification ratio is 17. In the negative direction, it is observed that the reverse current is small and almost saturated, which indicates that the heterojunction has good rectifying characteristics.

Figure 3B shows the log-log I-V curve of the device. The plot exhibits three distinct regions depending on the junction bias voltage. At low forward voltages in region $\mathrm{I}(<0.55 \mathrm{~V})$, the power law of I V1.2 was observed, suggesting a transport mechanism obeying the ohmic law. The exponent of 1.2 greater than 1 could be attributed to the presence of defect states in the interfaces, which might lead to some additional current at forward voltages. For region II $(0.55 \mathrm{~V}<\mathrm{V}<2.42 \mathrm{~V})$, the current followed an exponential relation $\mathrm{I} \sim \exp (\alpha \mathrm{V})$, and this relation was usually proposed for the wide band gap $\mathrm{p}-\mathrm{n}$ diodes related to a recombination-tunneling mechanism. In region III beyond $2.42 \mathrm{~V}$, the current conduction was attributed to the spacecharge-limited current (SCLC) generally observed in wide band gap semiconductors (Ghosh et al., 2007). In the present case, the SCLC is mainly for a single-carrier (hole) injection because the concentration of holes is larger than that of electrons. 

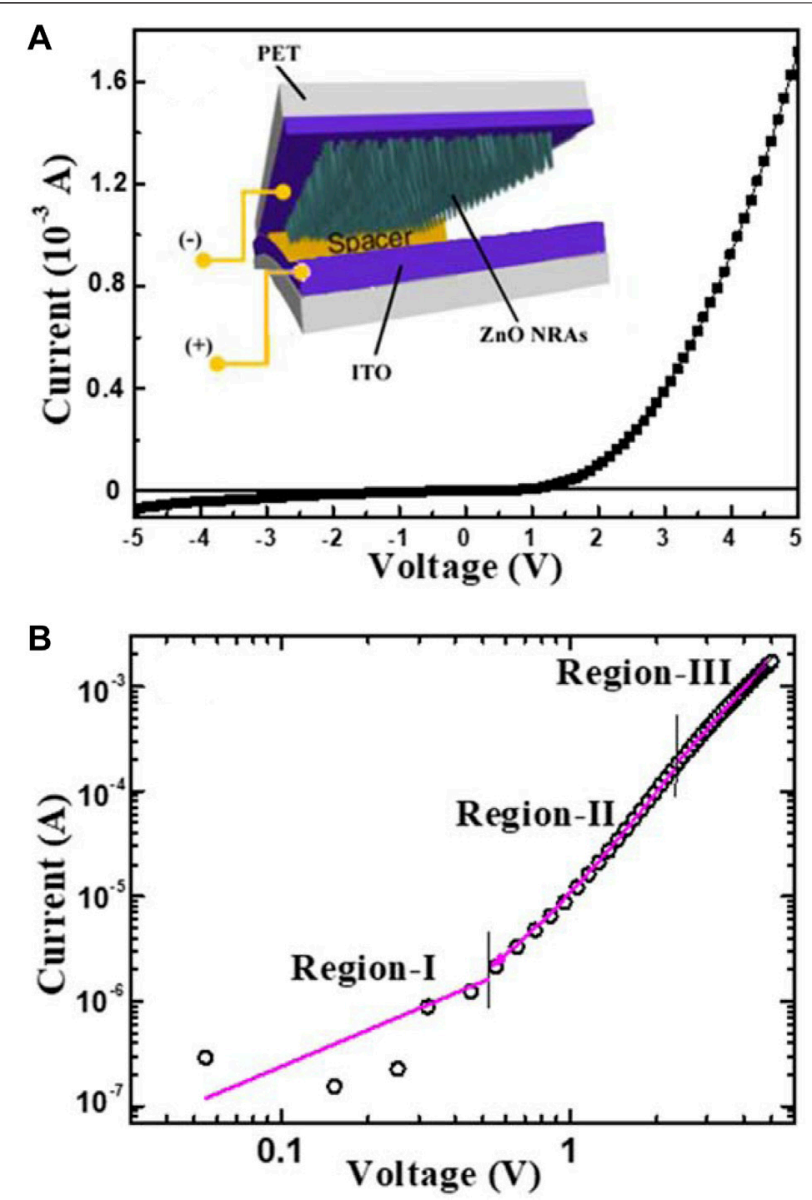

FIGURE 3| (A) $1-V$ characteristics of B-N ZnO on the ITO/PET substrate; the inset is the device structure schematic diagram; (B) log-log $1-V$ curve of the system.

\section{CONCLUSION}

In conclusion, $\mathrm{B}-\mathrm{N}$ co-doped $\mathrm{ZnO}$ was prepared on the ITO/PET substrate by the hydrothermal method. Based on light transmittance for ZnO NRA ITO/PET used in optoelectronic

\section{REFERENCES}

Beitollahi, H., Tajik, S., Nejad, F. G., and Safaei, M. (2020). Recent Advances in ZnO Nanostructure-Based Electrochemical Sensors and Biosensors. J. Mater. Chem. B. 8 (27), 5826-5844. doi:10.1039/D0TB00569J

Bian, J. M., Li, X. M., Gao, X. D., Yu, W. D., and Chen, L. D. (2004). Deposition and Electrical Properties of N-In Codoped P-type ZnO Films by Ultrasonic spray Pyrolysis. Appl. Phys. Lett. 84 (4), 541-543. doi:10.1063/1.1644331

Blöchl, P. E. (1994). Projector Augmented-Wave Method. Phys. Rev. B. 50 (24), 17953-17979. doi:10.1103/physrevb.50.1795

Chiu, C. H., Yu, P., Kuo, H. C., Chen, C. C., Lu, T. C., Wang, S. C., et al. (2008). Broadband and Omnidirectional Antireflection Employing Disordered GaN Nanopillars. Opt. Express. 16(12), 8748-8754. doi:10.1364/OE.16.008748

Du, J. L., Yu, H. H., Liu, B. S., Hong, M. Y., Liao, Q. L., Zhang, Z., et al. (2020). Strain Engineering in 2D Material-Based Flexible Optoelectronics. Small Methods 5 (1), 2000919. doi:10.1002/smtd.202000919 devices, the average light transmittance is $85 \%$ in the range of $850-1,000 \mathrm{~nm}$. In addition, through the first-principle calculation, doping of $\mathrm{B}$ and $\mathrm{N}$ leads to the lattice distortion of $\mathrm{ZnO}$ and further results in the generation of dipole, which hinders the electron-hole recombination and effectively separates the hole-electron pairs, thus affecting the photoelectric properties of $\mathrm{ZnO}$. Compared with those of intrinsic $\mathrm{ZnO}$, the band gap of $\mathrm{B}-\mathrm{N}$ co-doped $\mathrm{ZnO}$ is reduced and the conductivity is enhanced. In addition, the photogenerated carriers are effectively separated, thus enhancing the photoelectric effect of $\mathrm{ZnO}$. The rectification characteristics of B-N co-doped $\mathrm{ZnO}$ ITO/PET in the I-V curve are also studied in detail.

\section{DATA AVAILABILITY STATEMENT}

The original contributions presented in the study are included in the article/Supplementary Material, and further inquiries can be directed to the corresponding author.

\section{AUTHOR CONTRIBUTIONS}

$\mathrm{JJ}$ and QYu conceptualized the idea. JJ, JL, and QYu performed the methodology. JJ, JL, and PR performed formal analysis. JJ computed the data and wrote the original draft. JL investigated the data. JL and QYa supervised the work. PR visualized the results. KW and QYa obtained the resources. KW acquired the funding. QYa curated the data. QYu validated the results, reviewed and edited the paper, and administered the project.

\section{FUNDING}

This work was financially supported by the National Natural Science Foundation of China (Grant no. 51502166), Open Project Program of Fujian Key Laboratory of Functional Marine Sensing Materials (Grant no. MJUKF-FMSM202002), and Scientific Research Program Funded by Shaanxi Provincial Department (Grant no. 17JK0130)

Farooq, M. U., Atiq, S., Zahird, M., Kiani, M. S., Ramay, S. M., Zou, B. S., et al. (2020). Spin-polarized Exciton Formation in Co-doped GaN Nanowires. Mater. Chem. Phys. 245, 122756. doi:10.1016/ j.matchemphys.2020.122756

Ghosh, R., and Basak, D. (2007). Electrical and Ultraviolet Photo Response Properties of Quasi Aligned $\mathrm{ZnO}$ Nanowires/p-Si Heterojunction. Appl. Phys. Lett. 90 (24), 243106. doi:10.1063/1.2748333

Hwang, S. H., Kim, Y. K., Hong, S. H., and Sang, K. L. (2020). Effect of the Morphology and Electrical Property of Metal-Deposited ZnO Nanostructures on CO Gas Sensitivity. Nanomaterials 10 (11), 2124. doi:10.3390/nano10112124

Kaur, M., Kumar, V., Kaur, P., Lal, M., Negi, P., and Sharma, R. (2021). Effect on the Dielectric Properties Due to In-N Co-doping in ZnO Particles. J. Mater. Sci. Mater. Electron. 32 (7), 8991-9004. doi:10.1007/s10854-021-05570-w

Keskenler, E. F., Aydin, S., and Turgut, G. (2014). Optical and Structural Properties of Bismuth Doped $\mathrm{ZnO}$ Thin Films by Sol-Gel Method: Urbach Rule as a Function of Crystal Defects. ACTA PHYS. POL. A. 126 (3), 782-786. doi:10.12693/APhysPolA.126.782 
Klingshirn, C. (2010). The Luminescence of ZnO under High One- and Two Quantum Excitation. Scripta Mater. 71 (2), 547-556. doi:10.1002/ pssb.2220710216

Lee, H. K., Kim, M. S., and Yu, J. S. (2011). Effect of AZO Seed Layer on Electrochemical Growth and Optical Properties of ZnO Nanorod Arrays on ITO Glass. Nanotechnology 22 (44), 445602. doi:10.1088/0957-4484/22/44/ 445602

Liu, G. X., Shan, F. K., Lee, W. J., Shin, B. C., Kim, H. S., and Kim, J. H. (2008). Boron and Nitrogen Co-doped $\mathrm{ZnO}$ Thin Films for Opto-Electronic Applications. Ceram. Int. 34 (4), 1011-1015. doi:10.1016/ j.ceramint.2007.09.095

Marciel, A., Graça, M., Bastos, A., Pereira, L., Kumar, J. S., Borges, J., et al. (2021). Molybdenum Oxide Thin Films Grown on Flexible ITO-CoatedPET Substrates. Materials 14 (4), 821. doi:10.3390/ma14040821

Nripasree, N., and Kannoth, D, N. (2017). B-N Codoped P Type ZnO Thin Films for Optoelectronic Applications. Mater. Res. 21, 1. doi:10.1590/1980-5373-mr2017-0618

Perdew, J. P., Burke, K., and Ernzerhof, M. (1998). Perdew, Burke, and Ernzerhof Reply. Phys. Rev. Lett. 80 (4), 891. doi:10.1103/physrevlett.80.891

Prakash, T., Nerl, G., and Bonavitaa, A (2015). Structural, Morphological and Optical Properties of Bi-doped ZnO Nanoparticles Synthesized by a Microwave Irradiation Method. J. MATER. Sci-mater EL 26 (7), 4913-4921. doi:10.1007/ s10854-015-3002-7

Ra, Y. H., and Lee, C. R. (2020). Core-Shell Tunnel Junction Nanowire WhiteLight-Emitting Diode. Nano Lett. 20 (6), 4162-4168. doi:10.1021/ acs.nanolett.0c00420

Sahu, R., Gholap, H. B., Mounika, G., Dileep, K., Vishal, B., Ghara, S., et al. (2016). Stable P-type Conductivity in B and N Co-doped ZnO Epitaxial Thin Film. Phys. Status Solidi B. 253 (3), 504-508. doi:10.1002/pssb.201552625

Segal, M. D., Lindan, P. J. D., Probert, M. J., Pickard, C. J., Hasnip, P. J., Clark, S. J., et al. (2002). First-principles Simulation: Ideas, Illustrations and the CASTEP Code. J. Phys. Condens. Matter. 14 (11), 2717-2744. doi:10.1088/0953-8984/14/11/301

Sima, M., Vasile, E., and Sima, M. (2013). ZnO Films and Nanorod/shell Arrays Electrodeposited on PET-ITO Electrodes. Mater. Res. Bull. 48 (4), 1581-1586. doi:10.1016/j.materresbull.2012.12.045

Siva, N., Sakthi, D., Ragupathy, S., Arun, V., and Kannadasan, N. (2020). Synthesis, Structural, Optical and Photocatalytic Behavior of Sn Doped ZnO Nanoparticles. Mater. Sci. Eng. B. 253, 114497. doi:10.1016/j.mseb.2020.114497

Soudi, J., Sandeep, K. M., Sarojini, B. K., Patil, P. S., Maidur, S. R., and Balakrishna, K. M. (2021). Thermo-optic Effects Mediated Self Focusing Mechanism and Optical Power Limiting Studies of ZnO Thin Films Deposited on ITO Coated PET Substrates by RF Magnetron Sputtering under Continuous Wave Laser Regime. Optik 225, 165835. doi:10.1016/j.ijleo.2020.165835

Sun, B., and Li, C. M. (2015). Light-controlled Resistive Switching Memory of Multiferroic $\mathrm{BiMnO}_{3}$ Nanowire Arrays. Phys. Chem. Chem. Phys. 17 (10), 6718-6721. doi:10.1039/c4cp04901b
Tian, R. Y., and Zhao, Y. J. (2009). The Origin of P-type Conduction in (P, N) Codoped ZnO. J. Appl. Phys. 106, 021106. doi:10.1063/1.3195060

Wang, T. Y., Meng, J. L., He, Z. Y., Chen, L., Zhu, H., Sun, Q. Q., et al. (2020). Room-temperature Developed Flexible Biomemristor with Ultralow Switching Voltage for Array Learning. Nanoscale 12 (16), 9116-9123. doi:10.1039/ D0NR00919A

Wang, W., Ai, T. T., and Yu, Q. (2017). Electrical and Photocatalytic Properties of boron-doped ZnO Nanostructure Grown on PET-ITO Flexible Substrates by Hydrothermal Method. Sci. Rep. 7 (1), 42615. doi:10.1038/srep42615

Wróbel, J., Kurzydłowski, K. J., Hummer, K., Kresse, G., and Piechota, J. (2009). Calculations of $\mathrm{ZnO}$ Properties Using the Heyd-Scuseria-Ernzerhof Screened Hybrid Density Functional. Phys. Rev. B. 80 (15), 155124. doi:10.1103/ PhysRevB.80.155124

Xu, Z. C., Hou, Q. Y., and Qu, L. F. (2017). Effects on the Optical Properties and Conductivity of Ag-N Co-doped ZnO. Int. J. Mod. Phys. B. 31 (3), 1750008. doi:10.1142/s0217979217500084

Yamamoto, T., and Katayama-Yoshida, H. (2001). Physics and Control of Valence States in ZnO by Codoping Method. PHYSICA B 302-303, 155-162. doi:10.1016/S0921-4526(01)00421-5

Yan, Y., Li, J., Wei, S. H., and Al, J. M. (2007). Possible Approach to Overcome the Doping Asymmetry in Wideband gap Semiconductors. Phys. Rev. Lett. 98 (13), 135506. doi:10.1103/PhysRevLett.98.135506

Zhang, J. H., Zhao, G. Y., Li, Y. P., Ai, T. T., Wu, Cb., Jia, J. Q., et al. (2017a). Study on the Electrical Properties of Nano ZnO/PET-ITO Heterojunction Prepared by Hydrothermal Method. J. Electron. Spectrosc. Relat. Phenom. 235, 68-72. doi:10.1016/j.elspec.2019.04.006

Zhang, L., Kong, H., Qiao, M., Ding, X., and Yu, M. (2020). Supercritical $\mathrm{CO}_{2}$ induced Nondestructive Coordination between $\mathrm{ZnO}$ Nanoparticles and Aramid Fiber with Highly Improved Interfacial-Adhesion Properties and UV Resistance. Appl. Surf. Sci. 521, 14630. doi:10.1016/j.apsusc.2020.146430

Zhang, W., Liang, P. P., Li, H., Yang, X., Qiu, Y., Xu, N., et al. (2017b). Spectroscopic Studies of the Plasma for the Preparation of Al-N Co-doped ZnO Films. Spectrochimica Acta B: At. Spectrosc. 131, 48-57. doi:10.1016/ j.sab.2017.03.004

Conflict of Interest: The authors declare that the research was conducted in the absence of any commercial or financial relationships that could be construed as a potential conflict of interest.

Copyright (c) 2021 Jiang, Jiang, Rong, Wu, Yang and Yu. This is an open-access article distributed under the terms of the Creative Commons Attribution License (CC $B Y)$. The use, distribution or reproduction in other forums is permitted, provided the original author(s) and the copyright owner(s) are credited and that the original publication in this journal is cited, in accordance with accepted academic practice. No use, distribution or reproduction is permitted which does not comply with these terms. 